\title{
Traffic noise decreases nestlings' metabolic rates in an urban exploiter
}

\author{
François Brischoux, Alizée Meillère, Andréaz Dupoué, Olivier Lourdais and Frédéric Angelier \\ F. Brischoux (francois.brischoux@gmail.com), A. Meillère, A. Dupoué, O. Lourdais and F. Angelier, Centre d'Etudes Biologiques de Chizé, \\ UMR 7372 CNRS-ULR, Villiers en Bois, France.
}

\begin{abstract}
High levels of anthropogenic noise produced in urban areas are known to negatively affect wildlife. Although most research has been focused on the disturbances of communication systems, chronic noise exposure can also lead to physiological and behavioural changes that have strong consequences for fitness. For instance, behavioural changes mediated by anthropogenic noise (e.g. quality of parental care) may alter development and could influence nestling phenotype. We tested if nestling metabolism was influence by traffic noise in an urban exploiter, the house sparrow Passer domesticus. We experimentally exposed breeding house sparrows from a rural area to a playback of traffic noise and we examined the impacts of this experimental procedure on metabolic rates and morphology of nestlings. We did not find an effect of traffic noise on the morphology of nestlings. Surprisingly, we found that disturbed nestlings had overall lower metabolic rates and mass-adjusted metabolic rates than undisturbed birds. Our results suggest a specific effect of noise exposure per se, rather than an indirect effect of anthropogenic noise through the quality of parental care. Both the proximate mechanisms and the ultimate consequences of such metabolic changes on nestlings remain unknown and deserve future experimental studies.
\end{abstract}

Compared to natural environments, urban areas are characterized by structural simplification (McKinney 2002), increased pollution (Roux and Marra 2007), obtrusive nocturnal light levels (Kempenaers et al. 2010), and disturbing anthropogenic noise (Barber et al. 2010); all of which are known to negatively affect wildlife (Grimm et al. 2008). Accordingly, species richness and diversity are overall reduced in urban environments (Marzluff and Ewing 2001, McKinney 2008).

High levels of anthropogenic noise have recently been highlighted as an 'urgent conservation priority' (Francis and Barber 2013). This is especially true, and well-studied, in avian species for which life-history traits strongly relies on acoustic communication (Catchpole and Slater 2008, Slabbekoorn 2013). Indeed, disturbances and interferences in avian communication systems have strong impacts on territorial establishment and defence (Mockford and Marshall 2009), mate choice and pair bonds (Swaddle and Page 2007), and parent-offspring communication (McIntyre et al. 2014) leading to overall reduced avian reproductive performances in noisy environments (Halfwerk et al. 2011). Noise pollution may also affect an organism through processes that are not directly connected to the disruption of communication channels. For instance, chronic noise exposure can produce specific physiological and behavioural effects that can have direct and indirect consequences for fitness (Kight and Swaddle 2011, Francis and Barber 2013).
Such effects include, but are not restricted to, higher stress levels, sleep perturbations, decreased immune response, cognitive deficits and physiological pathologies (reviewed by Kight and Swaddle 2011).

Among the various consequences of noise pollution on urban wildlife, recent studies have highlighted the importance of behavioural changes (see reviews by Barber et al. 2010, Francis and Barber 2013). Indeed, anthropogenic noise can increase vigilance and affect anti-predator behaviour in birds (Barber et al. 2010, Meillère et al. 2015). In turn, such behavioural changes can bear consequences for reproductive performances through decreased parental care (lower nest attendance, altered incubation, and reduced provisioning efficiency, Schroeder et al. 2012, Meillère et al. 2015). Consequences of altered parental care quality during embryonic development or nestling growth have been abundantly investigated (reviewed by Clutton-Brock 1991, DuRant et al. 2013). Poor incubation conditions may have consequences for hatching success, nestling phenotype, and may carry over to later life-history stages (Ardia et al. 2010). For instance, developmental temperature can affect embryonic energy use (Booth 1987, Eiby and Booth 2008, DuRant et al. 2011), immunity (Ardia et al. 2010, DuRant et al. 2012a) and metabolic rate (Booth 1987, Olson et al. 2006, DuRant et al. 2012b), and altered incubation conditions have been shown to influence nestlings' metabolic and growth rates (Nord and Nilsson 2011, DuRant et al. 2013). 
Overall, behavioural changes caused by anthropogenic noise, and especially lowered nest attendance, may alter incubation conditions (e.g. temperature); and thus, could influence nestling phenotype (e.g. metabolic rates and thus energy use, Booth 1987, Olson et al. 2006, DuRant et al. 2012 b). We experimentally manipulated noise exposure to test this hypothesis in an urban exploiter, the house sparrow Passer domesticus. We exposed free-living house sparrows from a rural area to either a playback of traffic noise or the natural background noise of the study site in order to produce contrasted propensity to stay on the nest when disturbed or different patterns of provisioning frequency (Schroeder et al. 2012, Meillère et al. 2015), and we examined the impact of this experimental procedure on metabolic rates, body size and body mass of nestlings. We predicted that noise exposure would affect nestling growth through decreased nest attendance and brood provisioning (Schroeder et al. 2012, Meillère et al. 2015). Moreover, lower nest attendance may decrease incubation quality, and therefore incubating temperature. Reduced incubation temperature and altered growth have both been associated with increased metabolic rates in previous studies (Nord and Nilsson 2011, DuRant et al. 2013). Alternatively, if noise exposure reduces growth of the nestlings, they could down-regulate their metabolic rate as a response to lower food availability (Brzek and Konarzewski 2001, Moe et al. 2004). Therefore, we predicted that nestlings reared under noisy conditions would display either higher (Nord and Nilsson 2011, DuRant et al. 2013) or lower metabolic rates (Brzek and Konarzewski 2001, Moe et al. 2004) than undisturbed nestlings.

\section{Material and methods}

\section{Experimental procedure}

Experimental noise exposure has been thoroughly described in a related article (Meillère et al. 2015). Briefly, we exposed wild house sparrows breeding in nest-boxes in a rural site (Centre d'Etudes Biologiques de Chizé, France, $46^{\circ} 09^{\prime} \mathrm{N}$, $0^{\circ} 24^{\prime} \mathrm{W}$, henceforth CEBC for simplicity) to two different sound treatments during their first breeding attempt (April-July 2013). Nest-boxes from the 'noise' treatment (henceforth disturbed nest-boxes, $n=6$ ) were submitted to a traffic noise recording while control nest-boxes $(n=13)$ were exposed to the natural background noise of the rural environment during the entire first breeding attempt (i.e. from nest construction to fledging). The traffic noise recording was played in a loop $6 \mathrm{~h}$ a day (from 9 to $12 \mathrm{am}$ and from 2 to $5 \mathrm{pm}$ ). As expected, the experimental treatment produced higher noise levels at the disturbed nest-boxes $(63.32 \pm 1.65 \mathrm{~dB}(\mathrm{~A}))$ as compared to control nest-boxes $(43.04 \pm 0.47 \mathrm{~dB}(\mathrm{~A}))$, but similar noise levels than those experienced by urban birds $(61.35 \pm 1.21 \mathrm{~dB}(\mathrm{~A})$, Meillère et al. 2015). Disturbed and control nest-boxes were located in the same site, limiting the confounding effects of other environmental factors. Except for the levels of background noise, all other factors were similar among the monitored nests (e.g. size, height, and orientation of the nest-boxes; vegetation; access to food; human activity; and predation pressure), and thus, the effects of noise were likely separated from other confounding variables. Overall, occupancy rates, clutch sizes and laying dates were similar among the 2 sound treatments (Meillère et al. 2015).

\section{Measurements}

Nests were inspected every day to monitor reproduction and nestlings were weighed (electronic balance: $\pm 0.1 \mathrm{~g}$ ) and measured (tarsus length, Vernier calliper: $\pm 0.1 \mathrm{~mm}$ ) when they were 3 and $9 \mathrm{~d}$ old. Over the night between the ninth and the tenth day after hatching, one nestling per nest was brought to the laboratory to measure oxygen consumption rates. To assess nestling resting metabolic rate (RMR), measurements were carried out at night when individuals were resting, in a post-absorptive state, at $30^{\circ} \mathrm{C}$ because this temperature lies in the thermo-neutral zone of this species (Hudson and Kimzey 1966). We deliberately chose to measure only one nestling per nest, and thus to reduce our statistical power, in order to limit the risk of nest desertion by the parents. RMR was measured following the methods described in Powolny et al. (2016). We used a multi-channel flow controller and meter ( $\pm 1 \mathrm{ml} \mathrm{min}{ }^{-1}$ ) (FlowBar-8, Sable Systems, Las Vegas, USA) to provide air at a constant influx $\left(298.51 \pm 1.44 \mathrm{ml} \mathrm{min}^{-1}\right)$ to each test chamber. The nestlings (a maximum of two individuals were measured per night) were placed in a test chamber (internal volume $1870 \mathrm{ml}$ ) in a climatic room set at the target temperature. One test chamber was empty to provide baseline recording. Birds were kept in total darkness to measure overnight oxygen consumption (from 8:00 pm to 6:00 am the following morning), allowing the nestlings to empty their digestive tract and get used to the experimental conditions. The expelled air of each test chamber was sequentially sampled using a gas flow switcher (RM-Multiplexer, Sable Systems, Las Vegas, USA), following this measurement sequence: 300s in empty chamber (baseline air), $300 \mathrm{~s}$ in chamber with nestling no. $1,300 \mathrm{~s}$ in chamber with nestling no. 2, $300 \mathrm{~s}$ in empty chamber (baseline air). This led to 10-15 replicates per individual throughout the night. The air was stripped of water by passing it through Drierite (W. A. Hammond Drierite, Xenia, $\mathrm{OH}$ ) before dried air was sent to the gas analyser $\left(\mathrm{O}_{2}\right.$ : FC10A and $\mathrm{CO}_{2}$ : CA10, Sable System, Las Vegas, USA). We used respirometric equations adapted to our setup (Powolny et al. 2016) to estimate bird $\mathrm{VO}_{2}(\mathrm{ml}$ $\left.\mathrm{min}^{-1}\right) \cdot \mathrm{O}_{2}$ analyser was calibrated before each measurement session with outside air $\left(\mathrm{O}_{2}\right.$ proportion $\left.=20.95 \%\right)$ for $2 \mathrm{~h}$. $\mathrm{CO}_{2}$ analyser was calibrated once before all measurement sessions with two types of air with known $\mathrm{CO}_{2}$ concentrations $\left(\mathrm{CO}_{2}\right.$ proportion $=0 \%$ and $\left.0.6 \%\right)$ for $2 \mathrm{~h}$. At the end of metabolic measurements, birds released in their respective nest-boxes.

\section{Analyses}

To compare nestling morphology between treatments, we used ANOVAs with tarsus length/body mass at day 9 as the dependent variables and treatment as the factor. Body condition (size-adjusted body mass) was investigated with an ANCOVA with body mass as the dependent variable, tarsus length as the covariate, and treatment as the factor. We also used repeated-measures ANOVAs with tarsus length/body 
mass measured at day 3 and day 9 as the dependent variables and treatment as the factor.

To compare RMR between treatments, we used ANOVAs with RMR as the dependent variable and treatment as the factor. We used a linear regression to investigate the relationship between nestling body mass and RMR and a homogeneity of slope test was performed to compare the slopes of this linear relationship between treatments. Finally, mass-adjusted RMR was examined with an ANCOVA with RMR as the dependent variable, body mass as the covariate, and treatment as the factor.

All analyses were performed with Statistica 12.

\section{Results}

\section{Body size, body mass, body condition and growth rates}

Nestling body size and body mass were similar between treatments (ANOVAs with tarsus length/body mass as the dependent variables, $\mathrm{F}_{1,17}=0.74, \mathrm{p}=0.40$ and $\mathrm{F}_{1,17}=0.17$, $\mathrm{p}=0.68$ respectively for tarsus length and body mass). Examining body condition (size-adjusted body mass) led to the same results as those on body mass and tarsus length (ANCOVA with body mass as the dependent variable and tarsus length as the covariate, $\mathrm{F}_{1,16}=1.16, \mathrm{p}=0.29$ ).

Similarly, both structural and weight growth rates were similar between treatments (repeated-measures ANOVAs with tarsus length/body mass measured at day 3 and day 9 as the dependent variables, effect of treatment $\mathrm{F}_{1,17}=0.29$, $p=0.59$, effect of time $F_{1,17}=251.03, p<0.0001$ and time $\mathrm{x}$ treatment interaction $\mathrm{F}_{1,17}=0.93, \mathrm{p}=0.35$ for tarsus length; and effect of treatment $\mathrm{F}_{1,17}=0.25, \mathrm{p}=0.62$, effect of time $\mathrm{F}_{1,17}=243.59, \mathrm{p}<0.0001$ and time $\times$ treatment interaction $\mathrm{F}_{1,17}=0.03, \mathrm{p}=0.86$ for body mass, Fig. 1).

\section{Metabolism}

Oxygen consumption rates were different between treatments (ANOVA with oxygen consumption rate as the

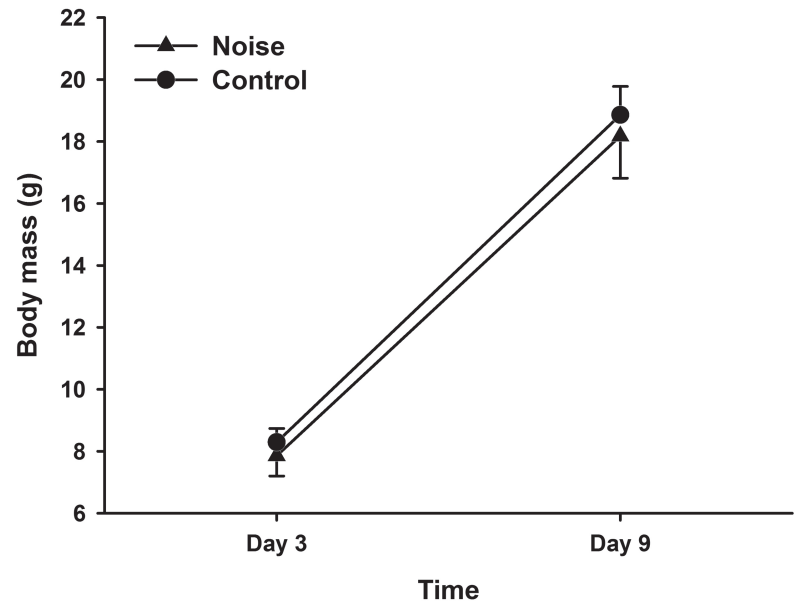

Figure 1. Body mass growth (mean \pm SE) between day 3 and day 9 of house sparrow nestlings exposed to natural rural background noise (control, $n=13$ ) or exposed to traffic noise (noise, $n=6$ ). dependent variable, $\mathrm{F}_{1,17}=4.36, \mathrm{p}=0.05$; noise treatment (mean $\pm \mathrm{SE}$ ): $\mathrm{VO}_{2}=0.93 \pm 0.33 \mathrm{ml} \mathrm{min}{ }^{-1}$; control: $\left.\mathrm{VO}_{2}=1.24 \pm 0.29 \mathrm{ml} \mathrm{min}^{-1}\right)$.

Oxygen consumption rates were associated with nestling body mass $\left(\mathrm{F}_{1,17}=37.02, \mathrm{r}^{2}=0.67, \mathrm{p}<0.0001\right.$, Fig. 2$)$. Homogeneity of slopes test indicated that the relationships between body mass and metabolic rate across treatments have similar slopes (interaction 'treatment $\times$ body mass', $\mathrm{F}_{1,15}=0.26, \mathrm{p}=0.61$, Fig. 2)

Correcting for body mass, oxygen consumption rates were also different between treatments (ANCOVA with oxygen consumption rate as the dependent variable and nestling body mass as the covariate, $\mathrm{F}_{1,16}=5.32, \mathrm{p}=0.035$, Fig. 3), with nestlings exposed to traffic noise having significantly lower mass-adjusted oxygen consumption rates as compared to control nestlings.

\section{Discussion}

Overall and surprisingly, we found that the noise treatment did not influence nestling growth, but that nestlings chronically exposed to traffic noise display a reduced RMR (whole organism and metabolic intensity) as compared to undisturbed nestlings. Although our a priori predictions involved a strong link between traffic noise and metabolism through altered postnatal developmental conditions (food provisioning and nutritional conditions, Brzek and Konarzewski 2001, Moe et al. 2004, Nord and Nilsson 2011, DuRant et al. 2013), our results rather suggest that the influence of traffic noise on metabolism was not directly mediated by nutritional deficit. Instead, other factors may be involved.

First, the effects of noise on metabolism could have been mediated through early developmental influences (e.g. prenatal parental care). For instance, incubation quality, and especially incubation temperature, is known to strongly influence embryonic development (Deeming and Fergusson 1991). Notably, suboptimal incubation temperatures reduce neonatal body condition, growth rates, and increase metabolic rates (Joseph et al. 2006, Olson et al. 2008, Nord and Nilsson 2011, see also Nord and Williams 2015). However,

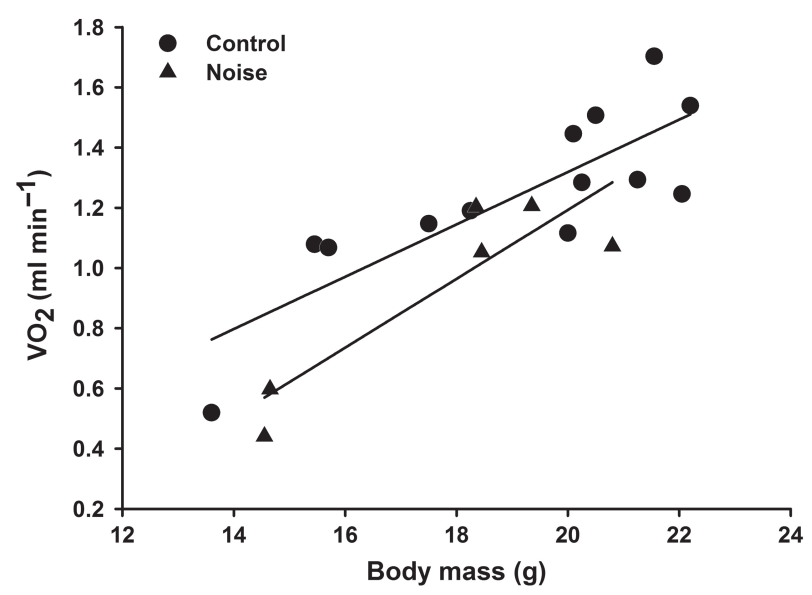

Figure 2. RMR in relation to body mass in house sparrow nestlings exposed to natural rural background noise (control, $n=13$ ) or exposed to traffic noise (noise, $n=6$ ). 


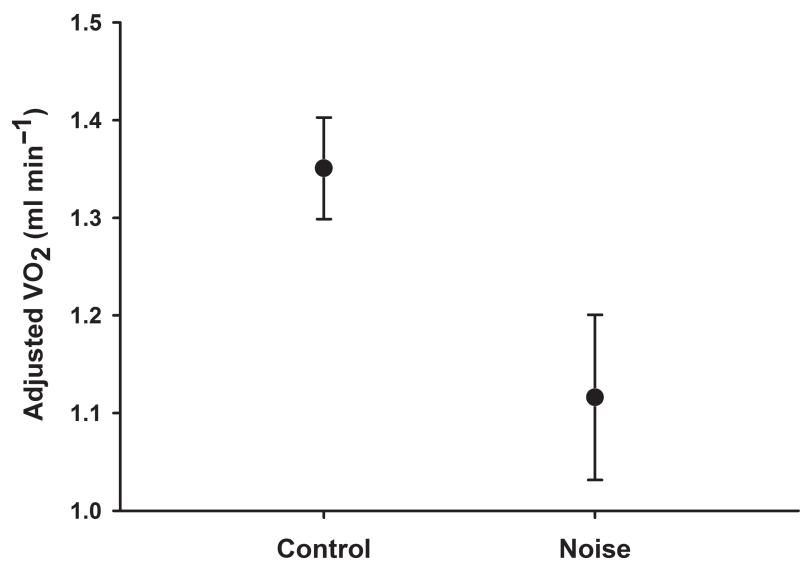

Figure 3. Mass-adjusted RMR (mean \pm SE) of house sparrow nestlings exposed to natural rural background noise (control, $n=13$ ) or exposed to traffic noise (noise, $n=6$ ). See text for details on the analyses.

our results do not fit with this hypothesis since we did not find any effect of traffic noise on growth rates, and an opposite effect of traffic noise on RMR. Future studies should therefore usefully expose developing birds to traffic noise either during incubation or during chick rearing period in order to disentangle the relative influences of pre- versus post-natal conditions on metabolic rates.

Second, relative organ size is a classical source of metabolic rate variation (Chappell et al. 1999, Careau et al. 2014). Although experimental and control nestlings were similar in overall body size, mass and condition, their body composition may have differed. For instance, control nestlings may have produced larger metabolically active organs (e.g. gut, intestines and liver, Russell and Chappell 2007). Unfortunately, we did not measure body composition of our studied individuals. Yet, the proximate mechanisms through which noise exposure could differentially influence relative organ growth remain puzzling.

Our results rather suggest a direct effect of noise exposure per se. Such specific influence could be linked to several proximate mechanisms such as higher stress levels, sleep perturbations, cognitive deficits, physiological pathologies or indeed a combination thereof (reviewed by Kight and Swaddle 2011). Therefore, our study suggests that reduced metabolism of developing birds in response to noise exposure is a major phenomenon to explore. For instance, a direct effect of noise exposure per se may have modified physiological regulations (including metabolic rate) to cope with high levels of background noise or, more generally, stress. Indeed, several studies have shown that metabolism can be under selection (Książek et al. 2004, Rønning et al. 2015). Thus, we suggest that background noise may modulate metabolic rates in individuals experiencing high levels of noise during their development (Soldatova 2011, Kesar 2014).

Although the proximate mechanisms leading to this direct impact of noise exposure on metabolism remain to be assessed, the ultimate consequences of such metabolic effects for nestlings also deserve future studies. Indeed, metabolism is known to be affected by developmental conditions with long-lasting effects until adulthood (Verhulst et al.
2006, Spencer and Verhulst 2008, Schmidt et al. 2012). In this context, it is crucial to assess the effects of noise exposure on metabolism as this trait is tightly linked to life history strategies and several fitness-related performances such as survival, reproduction, and offspring recruitment (Larivée et al. 2010, Rønning et al. 2015).

Acknowledgements - We are grateful to G. Gouchet and L. Sourisseau for their help for fieldwork.

Funding - Funding was provided by the Fondation Fyssen, the Région Poitou-Charentes, the Conseil Départemental des Deux-Sèvres, the ANR-16-CE02-0004-01 (Urbastress), and the Centre National de la Recherche Scientifique.

Permissions - All procedures were conducted in conformity with French laws and regulations and approved by the 'Comité d'éthique Poitou-Charentes' (approval number CE2013-3 to FA).

\section{References}

Ardia, D. R., Pérez, J. H. and Clotfelter, E. D. 2010. Experimental cooling during incubation leads to reduced innate immunity and body condition in nestling tree swallows. - Proc. R. Soc. B 277: 1881-1888.

Barber, J. R., Crooks, K. R. and Fristrup, K. M. 2010. The costs of chronic noise exposure for terrestrial organisms. - Trends Ecol. Evol. 25: 180-189.

Booth, D. T. 1987. Effect of temperature on development of mallee fowl Leipoa ocellata eggs. - Physiol. Zool. 60: 437-445.

Brzek, P. and Konarzewski, M. 2001. Effect of food shortage on physiology and competitive abilities of sand martin (Riparia riparia) nestlings. - J. Exp. Biol. 204: 3065-3074.

Careau, V., Killen, S. S. and Metcalfe, N. B. 2014. Adding fuel to the "fire of life": energy budgets across levels of variation in ectotherms and endotherms. - In: Martin, L. B., Woods, H. A. and Ghalambor, C. (eds), Integrative organismal biology. Wiley Scientific, pp. 219-233.

Catchpole, C. K. and Slater, P. J. 2008. Bird song: biological themes and variations. - Cambridge Univ. Press.

Chappell, M. A., Bech, C. and Buttemer, W. A. 1999. The relationship of central and peripheral organ masses to aerobic performance variation in house sparrows. - J. Exp. Biol. 202: 2269-2279.

Clutton-Brock, T. H. 1991. The evolution of parental care. - Princeton Univ. Press.

Deeming, D. C. and Fergusson, M. W. J. 1991. Egg incubation: its effects on embryonic development in birds and reptiles. - Cambridge Univ. Press.

DuRant, S. E., Hopkins, W. A. and Hepp, G. R. 2011. Energy expenditure of developing wood duck (Aix sponsa) embryos is related to incubation temperature. - Physiol. Biochem. Zool. 84: 451-457.

DuRant, S. E., Hopkins, W. A., Hawley, D. M. and Hepp, G. R. 2012a. Incubation temperature affects multiple measures of immunocompetence in wood duck ducklings. - Biol. Lett. 8: 108-111.

DuRant, S. E., Hopkins, W. A., Wilson, A. F. and Hepp, G. R. 2012b. Incubation temperature affects the metabolic cost of thermoregulation in a young precocial bird. - Funct. Ecol. 26: 416-422

DuRant, S. E., Hopkins, W. A., Hepp, G. R. and Walters, J. R. 2013. Ecological, evolutionary, and conservation implications of incubation temperature-dependent phenotypes in birds. - Biol. Rev. Camb. Phil. Soc. 88: 499-509.

Eiby, Y. A. and Booth, D. T. 2008. Embryonic thermal tolerance and temperature fluctuations in mounds of the Australian brush-turkey (Alectura lathami). - Auk 125: 594-599. 
Francis, C. D. and Barber, J. R. 2013. A framework for understanding noise impacts on wildlife: an urgent conservation priority. - Front. Ecol. Environ. 11: 305-313.

Grimm, N. B., Foster, D., Groffman, P., Grove, J. M., Hopkinson, C. S., Nadelhoffer, K. J., Pataki, D. E. and Peters, D. P. 2008. The changing landscape: ecosystem responses to urbanization and pollution across climatic and societal gradients. - Front. Ecol. Environ. 6: 264-272.

Halfwerk, W., Holleman, L. J. M., Lessells, C. and Slabbekoorn, H. 2011. Negative impact of traffic noise on avian reproductive success. - J. Appl. Ecol. 48: 210-219.

Hudson, J. W. and Kimzey, S. L. 1966. Temperature regulation and metabolic rhythms in population of the house sparrow, Passer domesticus. - Comp. Biochem. Physiol. 17: 203-217.

Joseph, N. S., Lourens, A. and Moran, E. T. 2006. The effects of suboptimal eggshell temperature during incubation on broiler chick quality, live performance, and further processing yield. - Poult. Sci. 85: 932-938.

Kempenaers, B., Borgström, P., Loës, P., Schlicht, E. and Valcu, M. 2010. Artificial night lighting affects dawn song, extra-pair siring success, and lay date in songbirds. - Curr. Biol. 20: $1735-1739$.

Kesar, A. G. 2014. Effect of prenatal chronic noise exposure on the growth and development of body and brain of chick embryo. - Int. J. Appl. Basic Med. Res. 4: 3-6.

Kight, C. R. and Swaddle, J. P. 2011. How and why environmental noise impacts animals: an integrative, mechanistic review. - Ecol. Lett. 14: 1052-1061.

Książek, A., Konarzewski, M. and Lapo, I. B. 2004. Anatomic and energetic correlates of divergent selection for basal metabolic rate in laboratory mice. - Physiol. Biochem. Zool. 77: 890-899.

Larivée, M. L., Boutin, S., Speakman, J. R., McAdam, A. G. and Humphries, M. M. 2010. Associations between over-winter survival and resting metabolic rate in juvenile North American red squirrels. - Funct. Ecol. 24: 597-607.

Marzluff, J. M. and Ewing, K. 2001. Restoration of fragmented landscapes for the conservation of birds: a general framework and specific recommendations for urbanizing landscapes. - Restor. Ecol. 9: 280-292.

McIntyre, E., Leonard, M. L. and Horn, A. G. 2014. Ambient noise and parental communication of predation risk in tree swallows, Tachycineta bicolor. - Anim. Behav. 87: 85-89.

McKinney, M. L. 2002. Urbanization, biodiversity, and conservation. - Bioscience 52: 883-890.

McKinney, M. L. 2008. Effects of urbanization on species richness: a review of plants and animals. - Urban Ecosyst. 11: $161-176$.

Meillère, A., Brischoux, F. and Angelier, F. 2015. Impact of chronic noise exposure on anti-predator behavior: an experiment in breeding house sparrows. - Behav. Ecol. 26: 569-577.

Mockford, E. J. and Marshall, R. C. 2009. Effects of urban noise on song and response behaviour in great tits. - Proc. R. Soc. B 276: 2979-2985.

Moe, B., Brunvoll, S., Mork, D., Brobakk, T. E. and Bech, C. 2004. Developmental plasticity of physiology and morphology in diet-restricted European shag nestlings (Phalacrocorax aristotelis). - J. Exp. Biol. 207: 4067-4076.

Nord, A. and Nilsson, J. A. 2011. Incubation temperature affects growth and energy metabolism in blue tit nestlings. - Am. Nat. 5: 639-651.

Nord, A. and Williams, J. B. 2015. The energetic costs of incubation. - In: Deeming, D. C. and Reynolds, J. S. (eds), Nests, eggs, and incubation: new ideas about avian reproduction. Oxford Univ. Press, pp. 152-170.

Olson, C. R., Vleck, C. M. and Vleck, D. 2006. Periodic cooling of bird eggs reduces embryonic growth efficiency. - Physiol. Biochem. Zool. 79: 927-936.

Olson, C. R., Vleck, C. M. and Adams, D. C. 2008. Decoupling morphological development from growth in periodically cooled zebra finch embryos. - J. Morphol. 269: 875-883.

Powolny, T., Bretagnolle, V., Dupoué, A., Lourdais, O. and Eraud, C. 2016. Cold tolerance and sex-dependent hypothermia may explain winter sexual segregation in a farmland bird. - Physiol. Biochem. Zool. 89: 151-160.

Rønning, B., Broggi, J., Bech, C., Moe, B., Ringsby, T. H., Pärn, H., Hagen, I. J., Sæther, B.-E. and Jensen, H. 2015. Is basal metabolic rate associated with recruit production and survival in free-living house sparrows? - Funct. Ecol. 30: 1140-1148.

Roux, K. E. and Marra, P. P. 2007. The presence and impact of environmental lead in passerine birds along an urban to rural land use gradient. - Arch. Environ. Contam. Toxicol. 53: 261-268.

Russell, G. A. and Chappell, M. A. 2007. Is BMR repeatable in deer mice? Organ mass correlates and the effects of cold acclimation and natal altitude. - J. Comp. Physiol. B 177: 75-87.

Schmidt, K. L., MacDougall-Shackleton, E. A. and MacDougallShackleton, S. A. 2012. Developmental stress has sex-specific effects on nestling growth and adult metabolic rates but no effect on adult body size or body composition in song sparrows. - J. Exp. Biol. 215: 3207-3217.

Schroeder, J., Nakagawa, S., Cleasby, I. R. and Burke, T. 2012. Passerine birds breeding under chronic noise experience reduced fitness. - PLoS One 7: e39200.

Slabbekoorn, H. 2013. Songs of the city: noise-dependent spectral plasticity in the acoustic phenotype of urban birds. - Anim. Behav. 85: 1089-1099.

Soldatova, I. B. 2011. Development and metabolism of chicken embryos in the embryogenesis under acoustic stimulation. - Russ. J. Develop. Biol. 42: 261

Spencer, K. A. and Verhulst, S. 2008. Post-natal exposure to corticosterone affects standard metabolic rate in the zebra finch (Taeniopygia guttata). - Gen. Comp. Endocrinol. 159: $250-256$.

Swaddle, J. P. and Page, L. C. 2007. High levels of environmental noise erode pair preferences in zebra finches: implications for noise pollution. - Anim. Behav. 74: 363-368.

Verhulst, S., Holveck, M.-J. and Riebel, K. 2006. Long-term effects of manipulated brood size on metabolic rate in zebra finches. - Biol. Lett. 2: 478-480. 